\title{
Espaçamento de cultivo de milho forrageiro consorciado com forrageiras tropicais para produção de silagens ${ }^{1}$
}

\author{
João Paulo Ferreira ${ }^{2}$, Marcelo Andreotti ${ }^{3}$, Isabô Melina Pascoaloto ${ }^{4}$, Nídia Raquel Costa ${ }^{5}$, Jeferson \\ Garcia Augusto $^{6}$, Flávio Hiroshi Kaneko
}

\author{
${ }^{1}$ Submetido em 05-04-2017 e aprovado em 31-08-2017 \\ ${ }^{2}$ Prof. Dr., Faculdade de Ciências Sociais e Agrárias de Itapeva-SP. CEP: 18412-000. e-mail: \\ ferreirajpferreira@gmail.com \\ ${ }^{3}$ Prof. Dr., Faculdade de Engenharia, Universidade Estadual Paulista Júlio de Mesquita Filho (UNESP), Ilha \\ Solteira-SP. CEP: 15385-000. e-mail: dreotti@agr.feis.unesp.br \\ ${ }^{4}$ Doutoranda, Faculdade de Ciências Agronômicas (FCA), UNESP, Botucatu-SP. CEP: 18610-307. e-mail: \\ isabomelina@gmail.com \\ ${ }^{5}$ Pós-doutoranda, FCA, UNESP, Botucatu-SP. CEP: 18610-307. e-mail: nidiarcosta@gmail.com \\ ${ }^{6}$ Mestrando, APTA Bovino de Corte, Instituto de Zootecnia, Sertãozinho-SP. CEP: 14174-000. e-mail: \\ jefercv@hotmail.com \\ ${ }^{7}$ Prof. Dr., Universidade Federal do Triângulo Mineiro (UFMT), Iturama-MG. CEP: 38280-000. e-mail: \\ flavio.kaneko@ifms.edu.br
}

\begin{abstract}
Resumo - A produção agropecuária tem requerido cada vez mais alimentos de alto valor nutritivo que atendam à demanda dos animais de alta produtividade. A produção de silagem é uma alternativa viável, mas pode apresentar perdas nutricionais se não for bem executada. O objetivo com esse trabalho foi avaliar as perdas provenientes do processo de ensilagem de grãos úmidos e planta inteira de milho consorciado com forrageiras tropicais. $\mathrm{O}$ delineamento experimental foi em blocos casualizados, com tratamentos no esquema fatorial 2 x 2 , com seis repetições. Os tratamentos foram: milho semeado em dois espaçamentos entrelinhas na semeadura $(0,45$ e $0,90 \mathrm{~m})$ e em consórcio com Urochloa brizantha cv. Xaraés e Megathyrsus maximum cv. Tanzânia. Foram determinadas as porcentagens de cada fração da planta de milho e forrageiras. Ambos materiais foram adequadamente ensilados e mantidos lacrados por 60 dias. Foram mensuradas as perdas da silagem por gases e por efluentes e calculada a recuperação de matéria seca. A silagem de grãos úmidos apresentou maiores perdas por gases e menores perdas por efluentes que a silagem de planta inteira. A maior proporção do capim-tanzânia na massa final a ser ensilada não influenciou significativamente as perdas na silagem de planta inteira de milho. Quando bem compactada, a silagem de planta inteira com forrageiras tropicais não apresenta perdas significativas durante o processo de ensilagem.
\end{abstract}

Palavras-chave: Consórcio; Integração lavoura-pecuária; Megathyrsus maximum; Plantio direto; Urochloa brizantha.

\section{Losses in production of maize silage with tropical forages}

\begin{abstract}
The agricultural production has required increasingly high nutritional value foods that meet the demands of high productivity animals. The silage trading is a viable alternative but that may have high nutritional losses if not well produced. The aim of this study was to evaluate the losses from the silage process of high moisture grain and whole plant maize intercropped with tropical forages. The experimental design was a randomized block in factorial $2 \times 2 \times 2$ with four replications. The treatments were: corn seeded in two row spacings $(0.45$ and 0.90 m) and intercropping with Urochloa brizantha (Xaraés grass) and Megathyrsus maximum (Tanzânia grass). They determined the percentage of each fraction of the maize plant and forages. Both materials were properly packaged and kept sealed for 60 days. Losses of silage by gases and effluents and and dry matter losses were measured. The high moisture corn silage showed higher losses and lower gas losses effluents that whole plant silage. The largest proportion of Tanzânia grass in the final mass to be ensiled did not significantly influence the losses in the whole plant silage. When properly compacted, the whole plant silage with tropical forages does not have high losses during the ensiling process.
\end{abstract}

Keywords: Consortium; Integrated crop-livestock; Megathyrsus maximum; No-tillage; Urochloa brizantha.

Revista Agropecuária Técnica, Areia-PB, v. 38, n. 3, p. 133-141, 2017

DOI: 10.25066 /agrotec.v38i3.33694 


\section{Introdução}

O aumento da demanda por carne de qualidade a baixos custos tem levado o produtor agropecuário a buscar alternativas viáveis de aumentar a produtividade e se tornar competitivo no mercado internacional. Segundo Silva et al. (2010), a principal limitação para o aumento de produção de animais em pastagens tropicais, que representam a grande maioria dos animais comercializados no mundo, é a baixa disponibilidade de alimento com alto valor nutritivo em épocas de baixas precipitações.

Assim, uma das formas de reduzir a falta de alimento de qualidade no outono/inverno aos animais e reformar pastagens uma das alternativas é consórcio de plantas produtoras de grãos como o milho com forrageiras tropicais, pois como interpretado por Domingues et al. (2013) pela limitação no ganho de peso animal durante $\mathrm{o}$ período seco, a produção e fornecimento de silagem é uma ótima alternativa de suplementação. Também, de acordo com Pinto et al. (2007), o material a ser ensilado pode ser composto por gramíneas, leguminosas, e outras partes vegetais, além de resíduos agroindustriais ou qualquer outro material que tenha componentes requeridos para uma boa fermentação. Dentre as fontes para produção da silagem, o milho é destaque pela facilidade de cultivo, alta quantidade de cultivares adaptados a diferentes condições edafoclimáticas, alta produtividade de matéria verde e alto valor nutritivo e energético (FERREIRA et al., 2011; RABELO et al., 2012; SALVO et al., 2012).

$\mathrm{O}$ processo de ensilagem é definido por Moraes et al. (2013) como a forma de manter a qualidade e o valor nutritivo da forragem fresca. Dessa forma, para que a silagem seja de qualidade, o material a ser ensilado deve ser colhido no ponto ideal de maturação e compactado adequadamente para reduzir ao máximo possíveis perdas. Tais perdas, atribuídas ao processo da ensilagem, são quantificadas por Santos et al. (2008) por meio da transformação da matéria seca ou energia, em consequência da respiração residual durante o enchimento do silo e vedação, do tipo de fermentação, e da deterioração aeróbica durante a retirada de forragem do silo.

Entretanto, mesmo com a atenção voltada para uma boa compactação, as perdas são inevitáveis e a única alternativa que resta é mitigar ao máximo seus efeitos negativos na quantidade e qualidade do material ensilado. Há diversos fatores que podem influenciar no processo fermentativo e nas perdas das silagens, destacando-se: as diferenças genéticas vegetais (RUIZ et al., 2009), a composição química e ponto de colheita de cada planta (VILELA et al., 2008), o processo de compactação, o tempo de exposição ao ar antes e após a ensilagem (SCHOCKEN-ITURRINO et al., 2005).

Os efluentes produzidos na silagem contêm grandes quantidades de açúcares, ácidos orgânicos e proteínas (ZANINE et al., 2006) além de nutrientes passíveis de serem lixiviados da massa vegetal. Os gases, por sua vez, são resultados da degradação da matéria seca por microrganismos indesejados e resultam em perdas quantitativas para o produtor. Isto posto, $\mathrm{o}$ trabalho teve como objetivo comparar as perdas resultantes do processo de ensilagem de grãos úmidos e da planta inteira de milho advindos do consórcio com capim-xaraés e capim-tanzânia, sob condições idênticas de semeadura, condução e compactação, levando em consideração os diferentes componentes ensilados da planta e os respectivos teores de matéria seca.

\section{Material e Métodos}

$\mathrm{O}$ experimento foi situado em área irrigada (pivô central) na Fazenda de Ensino, Pesquisa e Extensão (FEPE), da Faculdade de Engenharia de Ilha Solteira (FEIS/UNESP), em Selvíria, MS, Brasil. O tipo climático da região é Aw, conforme classificação deKöppen, com verão chuvoso e inverno seco. Durante a condução do experimento foram obtidos junto à estação meteorológica situada na FEPE, os dados diários de temperatura máxima, média, mínima do ar, umidade relativa do ar e precipitação pluvial apresentados em decênios na Figuras 1.

Segundo o Sistema Brasileiro de Classificação de Solos (Embrapa, 2013), o solo da área experimental é um Latossolo Vermelho distrófico de textura argilosa; com histórico de 9 anos em Plantio Direto. Antes da instalação do experimento foram retiradas 20 amostras na camada de 0-20 $\mathrm{cm}$ de profundidade para caracterização da fertilidade, resistência a penetração, densidade e porosidade do solo, utilizando metodologia proposta por Raij et al. (2001), Stolf (1991) e Embrapa (1997), respectivamente. 


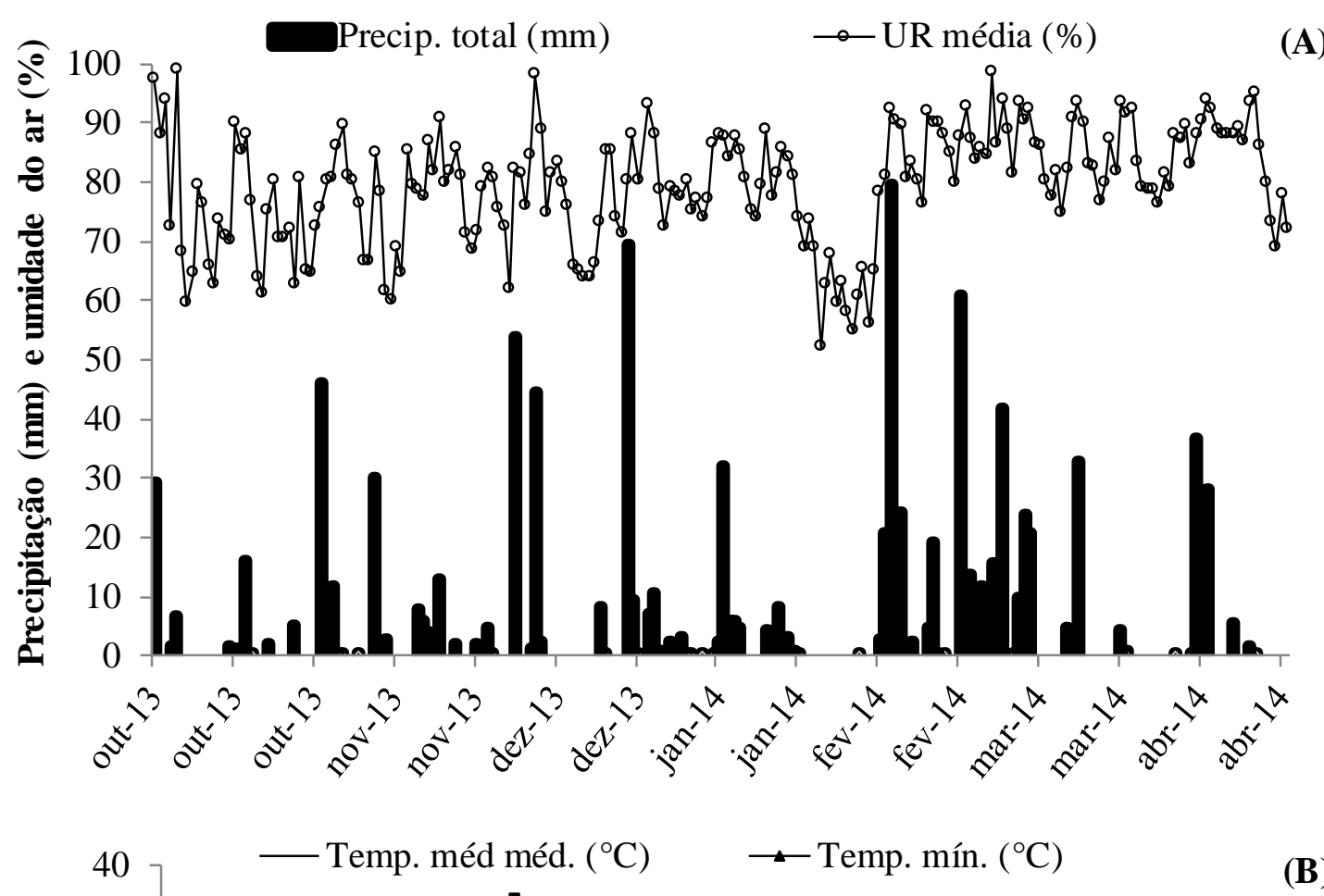

(A)

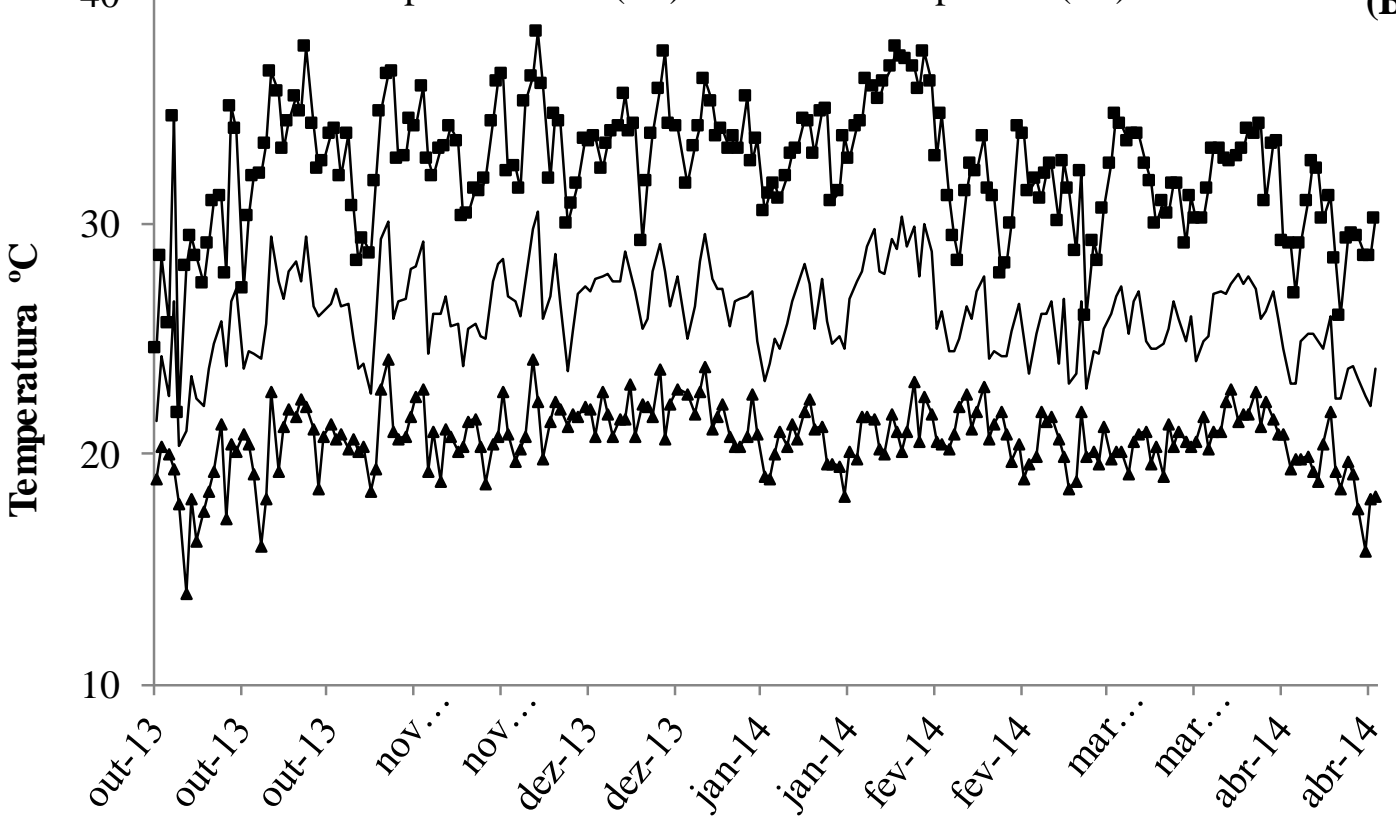

Figura 1 Informações meteorológicas do período do experimento, estação meteorológica da Fazenda de Ensino, Pesquisa e Extensão, UNESP, campus Ilha Solteira, MS.

$\mathrm{Na}$ análise do solo foram encontradas os seguintes atributos: $\mathrm{pH}\left(\mathrm{CaCl}_{2}\right)$ de 5,1; matéria orgânica $24 \mathrm{~g} \mathrm{dm}^{-3} ; \mathrm{H}+\mathrm{Al}, 27 \mathrm{mmol}_{\mathrm{c}} \mathrm{dm}^{-3} ; \mathrm{P}$ (resina), $31 \mathrm{mg} \mathrm{dm}^{-3} ; \mathrm{K}^{+}, \mathrm{Ca}^{2+} \mathrm{e} \mathrm{Mg}^{2+}, 4 ; 29$ e 15 mmol $_{\mathrm{c}} \mathrm{dm}^{-3}$, respectivamente; soma de bases, 48 $\mathrm{mmol}_{\mathrm{c}} \mathrm{dm}^{-3}$; capacidade de troca de cátions, 75 $\mathrm{mmol}_{\mathrm{c}} \mathrm{dm}^{-3}$; saturação por bases, $64 \%$, macroporosidade, microporosidade e porosidade total de 0,$08 ; 0,35$ e $0,43 \mathrm{~m}^{3} \mathrm{~m}^{-3}$, respectivamente; densidade do solo de $1,53 \mathrm{~kg} \mathrm{dm}^{-3}$; resistência mecânica a penetração de 3,2 Mpa e; umidade gravimétrica do solo de $209 \mathrm{~g} \mathrm{~kg}^{-1}$.

$\mathrm{O}$ delineamento experimental foi em blocos casualizados, com os tratamentos em esquema fatorial $2 \times 2$, com seis repetições. Os tratamentos foram: milho semeado em dois espaçamentos entrelinhas na semeadura $(0,45 \mathrm{e}$ 
0,90 m) e em consórcio ou com Urochloa brizantha cv. Xaraés ou Megathyrsus maximum cv. Tanzânia. As parcelas foram compostas por 7 linhas de milho no espaçamento de $0,45 \mathrm{~m}$ e por 4 linhas de milho no espaçamento de $0,90 \mathrm{~m}$ ambos, com $7 \mathrm{~m}$ de comprimento.

A cultura do milho (híbrido simples AG 8088 YG) foi semeada mecanicamente, após prévia dessecação das plantas daninhas da área experimental para formação de palhada, na profundidade de $0,03 \mathrm{~m}$, com 6,0 sementes $\mathrm{m}^{-1}$ no espaçamento de $0,90 \mathrm{~m}$ e 3,0 sementes $\mathrm{m}^{-1}$ no espaçamento de $0,45 \mathrm{~m}$, tanto para o milho para silagem de planta inteira, como para silagem de grãos úmidos. Foram aplicados $20 \mathrm{~kg} \mathrm{ha}^{-1} \mathrm{de} \mathrm{N}$, $70 \mathrm{~kg} \mathrm{ha}^{-1} \mathrm{de}_{2} \mathrm{O}_{5}$ e $40 \mathrm{~kg} \mathrm{ha}^{-1}$ de $\mathrm{K}_{2} \mathrm{O}\left(250 \mathrm{~kg} \mathrm{ha}^{-}\right.$ ${ }^{1}$ do formulado 08-28-16) durante a semeadura e $120 \mathrm{~kg} \mathrm{ha}^{-1}$ de $\mathrm{N}$ na forma de ureia a lanço em cobertura quando as plantas de milho apresentavam 6 folhas completamente desenvolvidas. As sementes de milho foram tratadas com $150 \mathrm{~g} \mathrm{~L}^{-1}$ i. a. imidacloprido $+450 \mathrm{~g}$ $\mathrm{L}^{-1}$ i.a. tiodicarbe e, quando necessário, foi realizada irrigação e pulverização para controle de insetos com $129 \mathrm{~g} \mathrm{ha}^{-1}$ i.a metomil $+24 \mathrm{~g} \mathrm{ha}^{-1}$ i.a. triflumurom.

A semeadura dos capins Xaraés e Tanzânia foi realizada simultaneamente nas entrelinhas do milho, com outra semeadora-adubadora com mecanismo sulcador do tipo disco duplo desencontrado para sistema plantio direto, nos espaçamentos de 0,34 e $0,17 \mathrm{~m}$ do milho de 0,90 e $0,45 \mathrm{~m}$ entrelinhas, respectivamente. Foram utilizados $7 \mathrm{~kg} \mathrm{ha}^{-1}$ de sementes puras viáveis, com valor cultural de 76 e $72 \%$ para o capimxaraés e Tanzânia, respectivamente, acondicionadas no compartimento do fertilizante da semeadora e depositadas na profundidade de $0,05 \mathrm{~m}$, garantindo a deposição abaixo das sementes de milho, com o intuito de atrasar a emergência dos capins, que neste trabalho teve uma defasagem de 7 dias da cultura principal, e diminuir a provável competição entre as espécies no período inicial de desenvolvimento das culturas.

A colheita foi realizada em dois momentos: ensilagem de planta inteira (grãos com 30-35\% de matéria seca) e ensilagem de grãos úmidos (grãos com $25 \%$ de umidade). No momento da colheita, as plantas de milho e forrageiras foram ceifadas em $1 \mathrm{~m}^{2}$ para determinação da porcentagem de cada espécie vegetal no material a ser ensilado, sendo as plantas de milho separadas em colmos, panículas, bainhas, lâmina foliar e espigas, sendo posteriormente calculados os teores de matéria seca do material a ser ensilado para ambas silagens. A colheita do material, milho e forrageiras, para ensilagem de planta inteira foi feita com colhedora de forragem (modelo JF 90) a $0,30 \mathrm{~m}$ do solo, enquanto que as espigas para ensilagem de grãos úmidos foram colhidas manualmente.

Ambos materiais foram adequadamente compactados $\left(600 \mathrm{~kg} \mathrm{~m}^{-3}\right)$ em baldes plásticos com capacidade para $15 \mathrm{~kg}$ de matéria verde com flanges de silicone adaptados nas tampas para permitir o escoamento de gases e sacos de algodão com areia no fundo para a recuperação do efluente, sendo mantidos lacrados pelo período de 60 dias até fermentação total do material. $\mathrm{Na}$ silagem de grãos úmidos, os grãos foram parcialmente triturados antes do acondicionamento nos baldes plásticos para facilitar a compactação. As determinações das perdas por gases, efluentes e o índice de recuperação da matéria seca foram realizados seguindo metodologia proposta por Jobim et al. (2007) da seguinte maneira:

$$
P G(\% \text { da MS })=\left[\frac{(M S C f-M S C a)}{(\text { MFe } x \text { TMSe })}\right] \times 100
$$

Onde: $\mathrm{PG}=$ perdas por gases durante a fermentação da silagem; MSCf = massa do silo cheio imediatamente após o fechamento; $\mathrm{MSCa}=$ massa do silo cheio imediatamente após a abertura; $\mathrm{MFe}=$ massa da forragem a ser ensilada; TMSe $=$ teor de MS da forragem a ser ensilada.

$$
P E(\mathrm{~kg} / \mathrm{t} \mathrm{MV})=\frac{[(M S V a-M S V f) x 1000]}{M V F e}
$$

Onde: $\mathrm{PE}=$ perdas por efluente durante a fermentação da silagem; MSVa = massa do silo vazio com o saco de areia imediatamente após a abertura, $\mathrm{MSVf}=$ massa do silo vazio com o saco de areia imediatamente após o fechamento; $\mathrm{MVFe}=$ massa verde de forragem a ser ensilada . 


$$
\operatorname{RMS}(\%)=\left[\frac{(M F a \times T M S a)}{(M F f \times T M S f)}\right] * 100
$$

Onde: RMS = índice de recuperação de matéria seca; $\mathrm{MFa}=$ massa de forragem imediatamente após a abertura do silo; $\mathrm{TMSa}=$ teor de MS no momento da abertura do silo; MFf = massa de forragem imediatamente após o fechamento do silo; $\mathrm{TMSf}=$ teor de MS da forragem no fechamento do silo.

Os resultados foram submetidos à análise de variância pelo teste $\mathrm{F}(\mathrm{p} \leq 0,05)$ e comparados pelo teste de Tukey $(\mathrm{p} \leq 0,05)$, utilizando o software SISVAR ${ }^{\circledR}$ (FERREIRA, 2014).

\section{Resultados e Discussão}

Analisando-se a Tabela 1, verifica-se efeito significativo dos capins em consórcio com o milho, em que o capim Xaraés, permitiu maior porcentagem de lâminas foliares de milho na massa vegetal a ser ensilada, enquanto que no consórcio do milho com capim Tanzânia houve incremento do percentual do capim na matéria seca de planta inteira, fato mais evidente também no espaçamento de $0,90 \mathrm{~m}$ entrelinhas do milho.
O conhecimento da proporção dos componentes da planta de milho e das forrageiras ensilados é importante pois altera o resultado final da qualidade da silagem de planta inteira, segundo Moraes et al. (2013) e tais dados são apresentados na Tabela 1. Observa-se que a participação da espiga foi maior que os demais componentes da planta, atingindo entre 43 e 46,6\%, o que representa uma quantidade alta de grãos no material a ser ensilado, embora as espigas também sejam constituídas de sabugo e palha.

Entretanto, embora dentro da mesma planta a proporção de espigas tenha sido maior, entre os consórcios não houve diferenças significativas para a porcentagem de colmos, panículas e bainhas e a porcentagem de espiga. $\mathrm{O}$ consórcio com capim-xaraés apresentou maior porcentagem de lâmina foliar de milho e menor quantidade de forrageira ensilada, se comparado ao consórcio com capim-tanzânia (Tabela 1). Tal resultado pode ser explicado pelo crescimento mais ereto e vigoroso do capim-tanzânia (GERDES et al., 2000), o que acarretou em maior competição com o milho, levando à um menor desenvolvimento das folhas de milho e senescência precoce das já desenvolvidas.

Tabela 1 Porcentagem de colmos, panículas e bainha (CPB), lâmina foliar (LF), espiga e forragens e teor de matéria seca do material a ser ensilado na silagem de planta inteira (MSp) e teor de matéria seca do material a ser ensilado na silagem de grão úmidos (MSg) do consórcio milho com capim-xaraés e capim-tanzânia em espaçamento de 0,45 e $0,90 \mathrm{~m}$, na silagem de planta inteira

\begin{tabular}{ccccccc}
\hline Consórcio & CPB & LF & Espiga & Forragens & MSp & MSg \\
CMX & $-30,72 \mathrm{a}$ & $8,92 \mathrm{a}$ & $46,61 \mathrm{a}$ & $13,75 \mathrm{~b}$ & $31,54 \mathrm{~b}$ & $20,41 \mathrm{a}$ \\
CMT & $27,48 \mathrm{a}$ & $7,74 \mathrm{~b}$ & $43,05 \mathrm{a}$ & $21,73 \mathrm{a}$ & $37,12 \mathrm{a}$ & $24,13 \mathrm{a}$ \\
Espaçamento & & & & & & \\
$0,45 \mathrm{~m}$ & $31,31 \mathrm{a}$ & $8,21 \mathrm{a}$ & $44,47 \mathrm{a}$ & $16,01 \mathrm{a}$ & $36,97 \mathrm{a}$ & $22,40 \mathrm{a}$ \\
$0,90 \mathrm{~m}$ & $26,80 \mathrm{~b}$ & $8,42 \mathrm{a}$ & $45,31 \mathrm{a}$ & $19,47 \mathrm{a}$ & $31,54 \mathrm{~b}$ & $21,12 \mathrm{a}$ \\
\hline & \multicolumn{6}{c}{ ANAVA $(\mathrm{p} \leq \mathrm{F})$} \\
\hline CMF & 0,605 & 0,023 & 0,133 & 0,048 & 0,042 & 0,196 \\
ESP & 0,016 & 0,667 & 0,619 & 0,363 & 0,045 & 0,283 \\
CMF x ESP & 0,754 & 0,997 & 0,129 & 0,418 & 0,231 & 0,564 \\
Bloco & 0,121 & 0,252 & 0,178 & 0,079 & 0,137 & 0,644 \\
Média & 29,15 & 8,31 & 44,83 & 17,71 & 34,33 & 22,02 \\
CV $(\boldsymbol{\%})$ & 10,37 & 10,82 & 9,66 & 31,45 & 15,20 & 19,88 \\
\hline
\end{tabular}

Médias seguidas pela mesma letra não diferem entre si pelo teste de Tukey $(\mathrm{p} \leq 0,05)$; CV (\%): Coeficiente de variação; CMF: Consórcio milho com forrageiras; CMX: Consórcio milho com capim-xaraés; CMT: Consórcio milho com capim-tanzânia; ESP: Espaçamento.

Os componentes da parede celular são os fatores de maior interferência na qualidade da matéria seca da planta de milho, sendo representados principalmente pela porcentagem de lignina, segundo Penalti (1995). Levando essa informação em consideração, o consórcio do milho com capim-tanzânia, por proporcionar menor crescimento de lâminas foliares e maior 
crescimento das hastes que são ricas em lignina, resulta em menor qualidade final do material de milho a ser ensilado, quando comparado ao consórcio com capim-xaraés. Pariz et al. (2009), estudando diferentes espécies de forrageiras consorciadas com o milho também observaram maior competição entre as plantas de milho com forrageiras do gênero Megathyrsus que com forrageiras do gênero Urochloa.

Com relação ao espaçamento, a única diferença significativa observada foi na proporção de colmos, panículas e bainhas, que foi maior para o espaçamento de $0,45 \mathrm{~m}$. Isso ocorre pois em espaçamentos menores a competição entre as plantas é maior e o sombreamento mais rápido, resultando em um crescimento maior em altura das plantas em busca de luz (estiolamento) (KAPPES et al. 2011), o que aumenta a proporção de colmos, levando também a um aumento de componentes fibrosos e uma redução na qualidade da silagem

Com base no teor de matéria seca do material a ser ensilado na modalidade planta inteira, houve diferenças significativas tanto para os consórcios como para o espaçamento. Embora teores elevados de água possam prejudicar a qualidade da silagem uma vez que interfere de forma negativa na fermentação, aumenta as perdas por efluentes e diminui o consumo voluntário pelo animal (SILVEIRA; LAVEZZO; SILVEIRA, 1980), enquanto que teores muito elevados de matéria seca podem indicar grande quantidade de fibras e componentes não digeríveis. O consórcio com capim-tanzânia em espaçamento de $0,45 \mathrm{~m}$ apresentou maior teor de matéria seca que os demais tratamentos. Isso acontece em espaçamentos menores porque há uma maior competição entre as plantas, o que leva a um estiolamento e uma produção menor de limbo foliar e maior de partes fibrosas da planta, aumentando o teor de matéria seca do material final se comparado ao espaçamento maior $(0,90$ $\mathrm{m})$.

Como a quantidade de limbo foliar é maior no capim-xaraés e como a quantidade de capimtanzânia é maior no material final a ser ensilado, o maior teor de matéria seca é observado na silagem do consórcio com o capim-xaraés, uma vez que essa espécie produz maior quantidade de hastes e materiais fibrosos, com menor teor de água, do que o limbo foliar. Com isso em vista, o consórcio com capim-xaraés em espaçamento de $0,90 \mathrm{~m}$, por apresentar menor quantidade de componentes fibrosos e maior quantidade de limbo foliar, pode resultar em silagens de qualidade superior.

As perdas por gases, por efluentes e a recuperação da matéria seca estão expostos na Tabela 2, tanto para a silagem de grãos úmidos, como para a silagem de planta inteira. Não foram observadas diferenças significativas para nenhum atributo analisado tanto nos consórcios como nos espaçamentos.

A recuperação de matéria seca representa quanto do material ensilado inicialmente ainda permanece disponível para utilização após a abertura do silo. Assim, quanto maior seu valor, melhor será a qualidade do processo de ensilagem e maior será a quantidade de silagem aproveitável, indicando indiretamente baixas perdas durante o processo fermentativo. Dessa forma, a silagem de planta inteira demonstrou superioridade com relação à silagem de grãos úmidos, que apresentou perdas de matéria seca durante a ensilagem próximas aos $56,9 \%$, contra os $18,5 \%$ da silagem de planta inteira.

Isso ocorreu, como demonstram os dados apresentados na Tabela 2, devido à maior perda por gases ocorrida na ensilagem de grãos úmidos, chegando a $65 \%$, contra os $14 \%$ da silagem de planta inteira, devido à dificuldade em homogeneização e padronização no interior do silo experimental dos grãos de milho mesmo triturados, criando espaços que poderiam alocar oxigênio e permitir a fermentação aeróbica indesejável.

Avaliando silagens de capim-marandu produzidas com quatro pressões de compactação $\left(100,120,140\right.$ e $\left.160 \mathrm{~kg}^{\mathrm{MS} \mathrm{m}} \mathrm{m}^{-3}\right)$ durante a ensilagem, Amaral et al. (2007) verificaram que as maiores produções de gases ocorreram nas silagens com menor compactação e maior espaço entre as partículas, o que foi observado entre os grãos nesse trabalho. Além do possível excesso de oxigênio, outra explicação está no teor de matéria seca elevado (75\% MS nos grãos úmidos). Van Soest (1994) observou que materiais com teores de matéria seca superiores a $40 \%$ são mais susceptíveis ao aquecimento e aparecimento de fungos que levam a reações indesejadas na fermentação. 
Tabela 2 Perdas por gases (PG), produção de efluentes (PE) e recuperação da matéria seca (RMS) no processo de ensilagem de planta inteira e de grãos úmidos do consórcio milho com o capim-xaraés e capim-tanzânia em espaçamento de 0,45 e $0,90 \mathrm{~m}$

\begin{tabular}{|c|c|c|c|c|c|c|}
\hline \multirow[b]{2}{*}{ Consórcio } & \multicolumn{3}{|c|}{ Silagem de planta inteira } & \multicolumn{3}{|c|}{ Silagem de grãos úmidos } \\
\hline & $\begin{array}{c}\text { PG } \\
(\% \mathrm{MS})\end{array}$ & $\begin{array}{c}\mathbf{P E} \\
\left(\mathrm{kg} \mathrm{t}^{-1} \mathrm{MV}\right)\end{array}$ & $\begin{array}{c}\text { RMS } \\
(\%)\end{array}$ & $\begin{array}{c}\mathbf{P G} \\
(\% \mathrm{MS})\end{array}$ & $\begin{array}{c}\mathbf{P E} \\
\left(\mathrm{kg} \mathrm{t}^{-1} \mathrm{MV}\right)\end{array}$ & $\begin{array}{c}\text { RMS } \\
(\%)\end{array}$ \\
\hline CMX & 14,33 & 2,35 & 79,16 & 64,00 & 1,64 & 42,49 \\
\hline CMT & 14,57 & 2,49 & 81,86 & 65,33 & 1,66 & 43,79 \\
\hline Espaçamento & ns & ns & ns & ns & ns & ns \\
\hline $0,45 \mathrm{~m}$ & 13,96 & 2,23 & 78,53 & 63,32 & 1,64 & 42,79 \\
\hline \multirow[t]{2}{*}{$0,90 \mathrm{~m}$} & 14,89 & 2,62 & 82,48 & 66,01 & 1,67 & 43,98 \\
\hline & \multicolumn{3}{|c|}{$\operatorname{ANAVA}(p \leq F)$} & \multicolumn{3}{|c|}{$\operatorname{ANAVA}(\mathrm{p} \leq \mathrm{F})$} \\
\hline $\mathrm{CMF}$ & 0,849 & 0,794 & 0,288 & 0,327 & 0,543 & 0,072 \\
\hline ESP & 0,330 & 0,473 & 0,133 & 0,066 & 0,600 & 0,300 \\
\hline CMF x ESP & 0,169 & 0,396 & 0,211 & 0,330 & 0,207 & 0,641 \\
\hline Bloco & 0,951 & 0,227 & 0,270 & 0,423 & 0,176 & 0,689 \\
\hline Média geral & 14,42 & 2,42 & 80,51 & 64,60 & 1,65 & 43,14 \\
\hline $\mathrm{CV}(\%)$ & 12,52 & 22,16 & 6,01 & 3,97 & 3,35 & 2,95 \\
\hline
\end{tabular}

Médias seguidas pela mesma letra não diferem entre si pelo teste de Tukey $(\mathrm{p} \leq 0,05)$; CV (\%): Coeficiente de variação; CMF: Consórcio milho com forrageiras; CMX: Consórcio milho com capim-xaraés; CMT: Consórcio milho com capim-Tanzânia; ESP: Espaçamento.

Todavia, a silagem de planta inteira apresentou perdas por efluentes quase $50 \%$ maiores que a silagem de grãos úmidos. A explicação está no teor de água do material a ser ensilado, que foi de $65 \%$ na planta inteira e de apenas $25 \%$ nos grãos úmidos, e de acordo com Van Soest (1994), o alto teor de água favorece a fermentação láctica inadequada e aumenta as perdas por efluentes e lixiviação dos nutrientes. Zanine et al. (2006) ainda afirmaram que ambientes com alta umidade, elevado $\mathrm{pH}$ e elevada temperatura facilitam o desenvolvimento de bactérias do gênero Clostridium, responsáveis por produzir gás carbônico e ácido butírico, levando também a perdas por gases, o que pode justificar as perdas encontradas na silagem de planta inteira no presente trabalho.

Os resultados desse trabalho diferem dos encontrados por Oliveira et al. (2009), que verificaram maiores perdas por efluentes que por gases, estudando silagens de capim-tanzânia amonizado, sendo os valores de perdas por gases de 7,5\% para silos sem o uso de ureia e de perdas por efluentes acima de $30 \%$, demonstrando que o consórcio do milho com a forrageira pode diminuir a perda de nutrientes por lixiviação.

Como não houve diferenças significativas entre tratamentos para as variáveis teor de matéria seca do material a ser ensilado, perdas por gases, por efluentes e recuperação da matéria seca para a silagem de grãos úmidos é possível afirmar que, com base nesses atributos, o uso de ambos espaçamentos e consórcios é recomendado, sem que haja distinção entre eles.

\section{Conclusão}

O uso de diferentes espaçamentos na semeadura do milho e seu consórcio com forrageiras tropicais (Xaraés e Tanzânia) não influencia as perdas para produção de silagem de planta inteira ou grãos úmidos;

A produção de silagem de grãos úmidos de milho apresenta maiores perdas por gases e de matéria seca que a silagem de planta inteira em consórcio com os capins Xaraés e Tanzânia;

Para silagem de planta inteira é recomendado o consórcio com capim-xaraés em espaçamento de $0,90 \mathrm{~m}$.

\section{Agradecimento}

À Fundação de Amparo à Pesquisa do Estado de São Paulo (FAPESP - Processo $\mathrm{n}^{\circ}$ 2012/12213-6) pela concessão de bolsa de pósgraduação para a realização desta pesquisa.

\section{Referência}

AMARAL, R. C. et al. Características fermentativas e químicas de silagens de capimmarandu produzidas com quatro pressões de compactação. Revista Brasileira de Zootecnia, v. 36, n. 3, p. 532-539, 2007. 
DOMINGUES, A. N. et al. Agronomic characteristics of corn hybrids for silage production in the State of Mato Grosso, Brazil. Acta Scientiarum. Animal Science, v. 35, n. 1, p. 7-12, 2013.

EMBRAPA. Centro Nacional de Pesquisa de Solos. Manual de métodos de análise de solo. Rio de Janeiro: CNPS, 1997. 212 p.

EMBRAPA. Centro Nacional de Pesquisa dos Solos. Sistema brasileiro de classificação de solos. Rio de Janeiro: Embrapa/CNPS, 2013. $353 \mathrm{p}$.

FERREIRA, D. F. Sisvar: a guide for its bootstrap procedures in multiple comparisons. Ciência e Agrotecnologia, v. 38, n. 2, p. 109-112, 2014.

FERREIRA, G. D. G. et al. Valor nutritivo da silagem de dez híbridos de milho. Acta scientiarum. Animal science, v. 33, n. 3, p. 255-260, 2011.

GERDES, L. et al. Avaliação de características agronômicas e morfológicas das gramíneas forrageiras Marandu, Setária e Tanzânia aos 35 dias de crescimento nas estações do ano. Revista Brasileira Zootecnia, v. 29, n. 4, p. 947-954, 2000.

JOBIM, C. C. et al. Avanços metodológicos na avaliação da qualidade da forragem conservada. Revista Brasileira de Zootecnia, v. 36, suppl.0, p. 101-119, 2007.

KAPPES, C. et al. Desempenho de híbridos de milho em diferentes arranjos espaciais de plantas. Bragantia, v.70, n.2, p.334-343, 2011.

MORAES, S. D. et al. Produção e composição química de híbridos de sorgo e de milho para silagem. Revista Brasileira de Saúde e Produção Animal, v. 14, n. 4, p. 624-634, 2013.

OLIVEIRA, H. C. et al. Perdas e valor nutritivo da silagem de capim-tanzânia amonizado com uréia. Archivos de Zootecnia, v. 58, n. 222, p. 195-202, 2009.

PARIZ, C. M. et al. Desempenhos técnicos e econômicos da consorciação de milho com forrageiras dos gêneros Panicum e Bachiaria em sistema de integração lavoura-pecuária. Pesquisa Agropecuária Tropical, v. 39, n. 4, p. 360-370, 2009.
PENALTI, M. A. Relação de alguns parâmetros agronômicos e bromatológicos de híbridos de milho (Zea mays L.,) com a produção, digestibilidade e teor de matéria seca da planta. São Paulo: Universidade de São Paulo, 1995. 97p.

PINTO, A. P. et al. Avaliação da silagem de bagaço de laranja e silagem de milho em diferentes períodos de armazenamento. Acta Scientiarum. Animal science, v. 29, n. 4, p. 371-377, 2007.

RABELO, C. H. S. et al. Perdas fermentativas e estabilidade aeróbia de silagens de milho inoculadas com bactérias ácido-láticas em diferentes estádios de maturidade. Revista Brasileira de Saúde e Produção Animal, v. 13, n. 3, p. 656-668, 2012.

RAIJ, B. Van et al. Análise química para avaliação da fertilidade de solos tropicais. Campinas: Instituto Agronômico, 2001. 284 p.

RUIZ, B. O. et al. Efectos de enzimas e inoculantes sobre la composición del ensilaje de maíz. Archivos de Zootecnia, v. 58, n. 222, p. 163-172, 2009

SALVO, P. A. R. et al. Características de silagens de milho inoculadas com Lactobacillus buchneri e L. plantarum. Archivos de Zootecnia, v. 62, n. 239, p. 379-390, 2013.

SANTOS, E. M. et al. Inoculante ativado melhora a silagem de capim-tanzânia (Panicum maximum). Archivos de Zootecnia, v. 57, n. 217, p. 35-42, 2008.

SCHOCKEN-ITURRINO, R. P. et al. Alterações químicas e microbiológicas nas silagens de capim-tifton 85 após a abertura dos silos. Revista Brasileira de Zootecnia, v. 34, n. 2, p. 464-471, 2005.

SILVA, J. J. et al. Produção de leite de animais criados em pastos no Brasil. Arquivo Brasileiro de Medicina Veterinária e Zootecnia, v. 17, n. 3, p. 26-36, 2010.

SILVEIRA, A. C.; LAVEZZO, W.; SILVEIRA, F. S. Consumo de silagem de capim elefante (Pennisetum purpureum Schum.), submetida a diferentes tratamentos. Revista Brasileira de Zootecnia, v. 9, p. 306-320, 1980.

STOLF, R. Teoria e teste experimental de fórmulas de transformação dos dados de penetrômetro de impacto em resistência do solo. 
Revista Brasileira de Ciência do Solo, v. 15, p. 229-235, 1991.

Van Soest, P. J. Nutritional Ecology of the Ruminant. 2 ed. Ithaca, NY: Cornell University, 1994. $476 \mathrm{p}$.

VILELA, H. H. et al. Valor nutritivo de silagens de milho colhido em diversos estádios de maturação. Revista Brasileira de Zootecnia, v. 37, n. 7, p. 1192-1199, 2008

ZANINE, A. M. et al. Efeito do farelo de trigo sobre as perdas, recuperação de matéria seca e composição bromatológica de silagem de capim-mombaça. Brazilian Journal of Veterinary Research and Animal Science, v. 43, n. 6, p. 803-809, 2006. 